\title{
DIAGNOSTIC OF CNC LATHE WITH QC 20 BALLBAR SYSTEM
}

\author{
Jerzy Józwik', Leszek Semotiuk', Ivan Kuric² \\ 1 Department of Production Engineering, Mechanical Engineering Faculty, Lublin University of Technology, \\ Nadbystrzycka Str. 36, 20-618 Lublin, Poland, e-mail: j.jozwik@pollub.pl \\ 2 Department of Automation and Production Systems, Faculty of Mechanical Engineering, University of Žilina, \\ Univerzitná Str. 1, 010-26 Žilina, Slovakia, e-mail: ivan.kuric@fstroj.utc.sk
}

Received: 2015.09.21

Accepted: 2015.11.14

Published: 2015.12.04

\begin{abstract}
This paper presents the evaluation of the influence of the feedmotion speed on the value of selected geometric errors of CNC lathe CTX 310 eco by DMG, indentified by QC 20 Ballbar system. Diagnostically evaluated were: the deviation of the axis squareness, reversal spike, and backlash. These errors determine the forming of the dimensional and shape accuracy of a machine tool. The article discusses the process of the $\mathrm{CNC}$ diagnostic test, the diagnostic evaluation and formulates guidelines on further CNC operation. The results of measurements were presented in tables and diagrams.
\end{abstract}

Keywords: CNC machine tool, CNC Lathe QC 20 Ballbar, diagnostics systems, accuracy, geometric errors, deviation, squareness, reversal spike, backlash.

\section{INTRODUCTION}

The diagnostics of $\mathrm{CNC}$ machines is the main task during the technological machine operation. Each machine tool during operation is prone to wearing down over a time span. Therefore, it should be tested periodically - and its geometric condition diagnosed at a required frequency. Both the machines already in operation as well as the machines ordered by buyers are diagnosed. Each such machine is tested and checked before it arrives at the customer's. Both contact and noncontact methods are used in tests [1-10]. Frequently, some of the measured errors need specialist testing methods, and in general, these are non-contact interferometric methods. The fundamental limitation of the stationary interferometric methods in the machine measurements is the considerable time amount needed to set the interferometer's optics, especially for the machines of a tooling range over a few meters. The possibility of measuring the whole tooling axis and obtaining error information at the full range motion [1-5] constitutes an undisputable advantage. The second group of diagnostic tools are the tools based on contact measurements. QC 20 Ballbar or Ballbar API Automated Precision Inc. or Ballbar DBB 110 by DMG are the examples of contact diagnostics and measurement systems (Fig. 1).

They enable recording the technical condition of machine tools, comparing and classifying various machine tools according to their capacity of providing required tooling precision. It is particularly essential in production companies with a big machine park because it allows moving the machining tasks of high-precision products to the machines which enable such high dimensional and shape accuracy [9-15].

\section{RESEARCH METHODOLOGY AND EXPERIMENTAL TESTS}

Experimental tests were conducted for $\mathrm{CNC}$ CTX 310 eco by DMG (Fig. 2). During the testing the diagnostic system QC 20 Ballbar was used norm defined as telescoping kinematic bar (Fig. 3).

Tests were conducted according to PN-ISO 230-4 standard. PN-ISO 230-4:1999 regulates $\mathrm{CNC}$ diagnostics according to roundness mea- 
a)

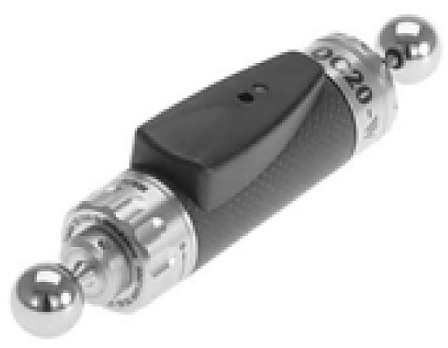

b)

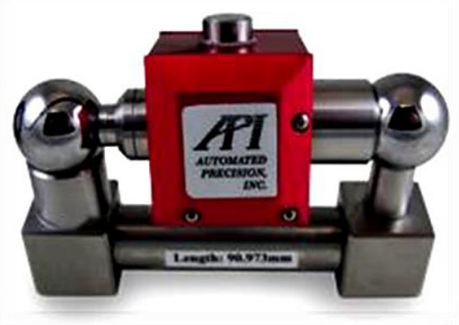

c)

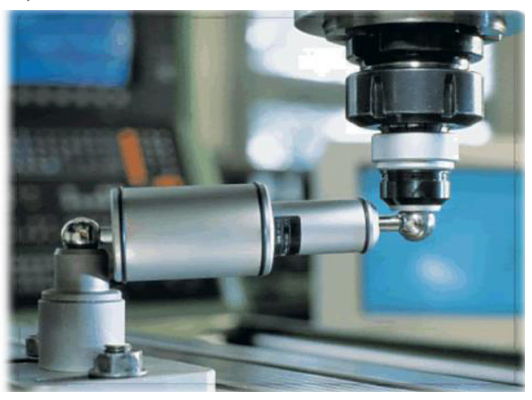

Fig. 1. CNC diagnostic systems: a) QC 20 Ballbar Renishaw, b) Ballbar API Automated Precision Inc.

c) Ballbar DBB 110 by DMG [6-16]

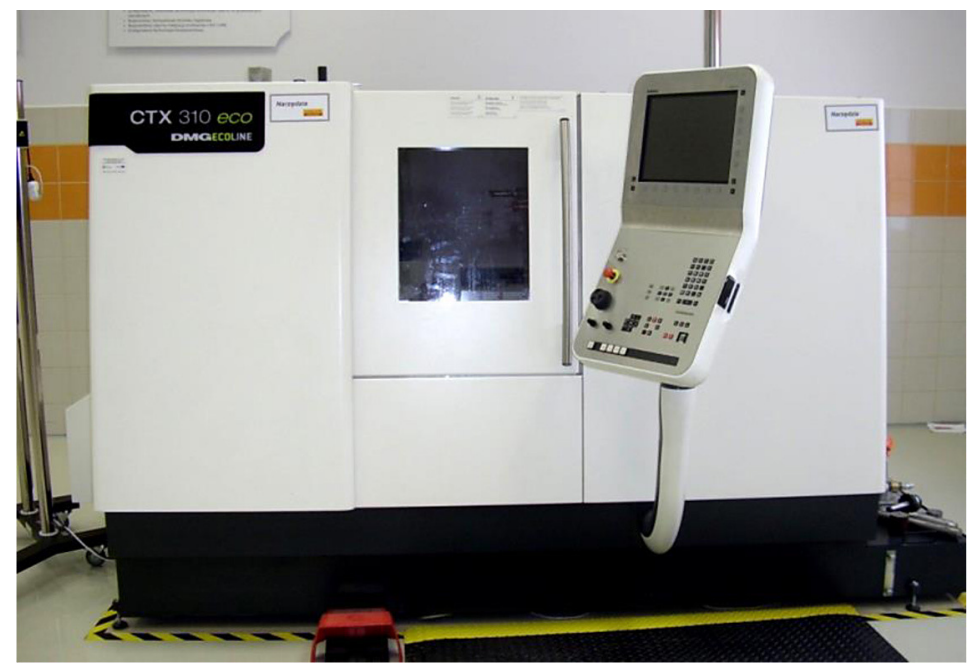

Fig. 2. Test stand, CTX 310 eco lathe by DMG
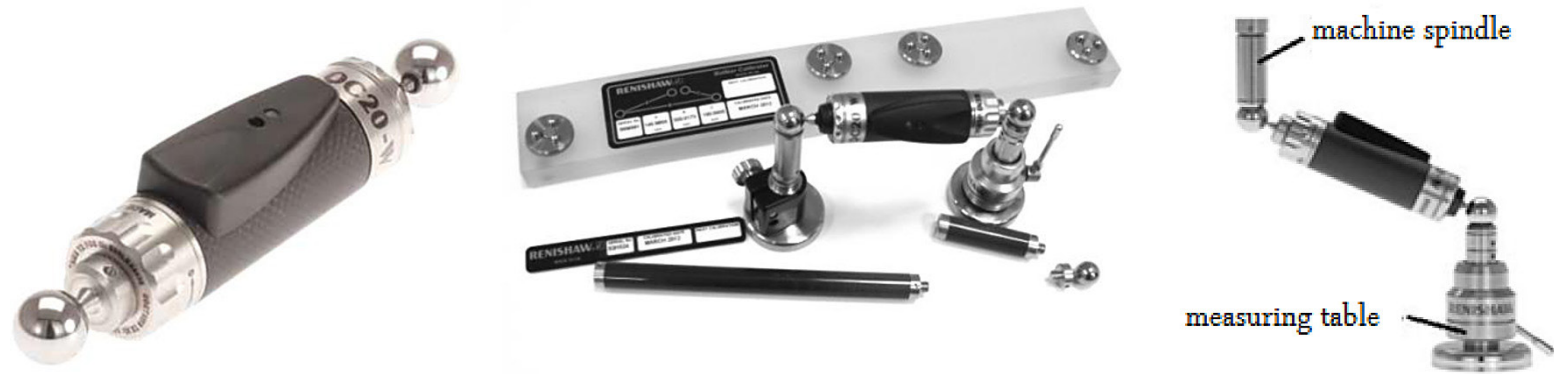

Fig. 3. QC 20 Ballbar diagnostic tool (kinematic telescoping bar)

surement in numerically controlled machine tools with the kinematic telescoping bar. The significant value was the feedmotion speed $v_{f}$. The value of the feedmotion speed was changed in the range of $500-2000 \mathrm{~mm} / \mathrm{min}$. The measurement results of particular errors were presented as diagrams.

Figure 4 presents QC 20 Ballbar measuring planes. These planes are universal, and after transformation are used with reference to $\mathrm{CNC}$ lathes. Figure 5 presents the experimental test on analysed CNC and the lathe kit of QC 20 Ballbar.

Analysed errors: squareness deviation of CNC CTX 310 eco axis, reversal spike and back- lash. During the identification of the squareness deviation of axis the diagnostic diagram takes the shape of the oval or the shape of a peanut rotated aslant at a $45^{\circ}$ or $135^{\circ}$ angle. The axis of the deviation of the diagram is the same for both directions of the circular interpolation cycle, clockwise as well as anticlockwise. The unit of the squareness error, $\mathrm{mm} / \mathrm{m}$, can be in the case of Renishaw software operating QC 20 Ballbar changed into any different unit in the test result (such as: angle in degrees, seconds, micrometre/ foot, micrometre/millimetre) by the proper setting of software parameters. The squareness er- 
a)

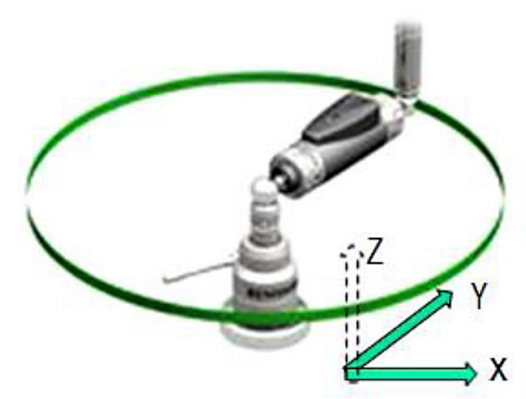

b)

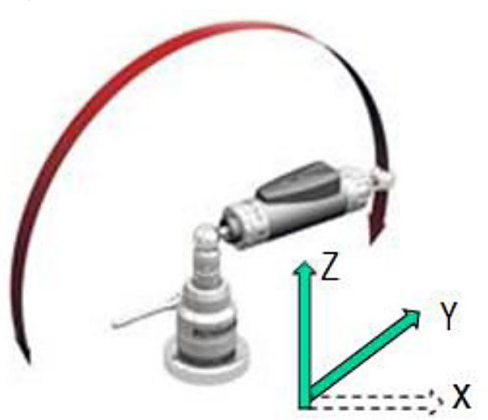

c)

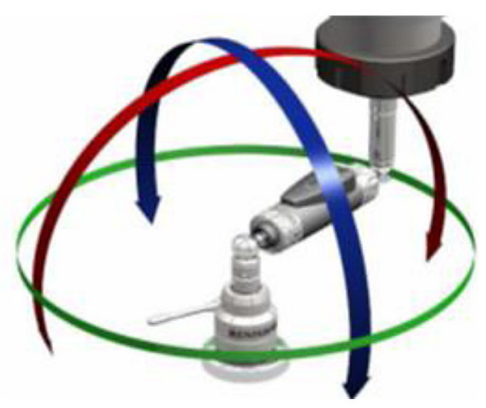

Fig. 4. QC 20 Ballbar measuring planes

a)

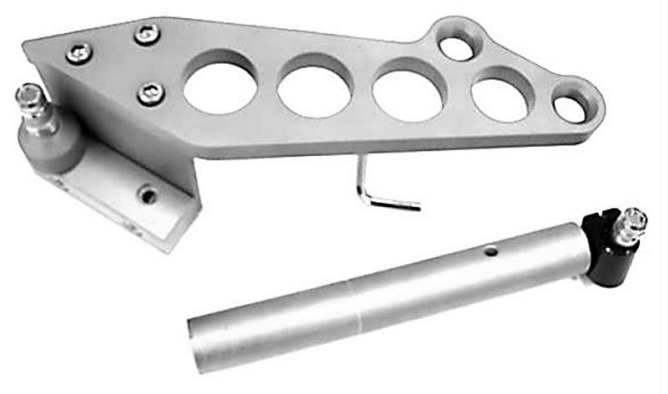

b)

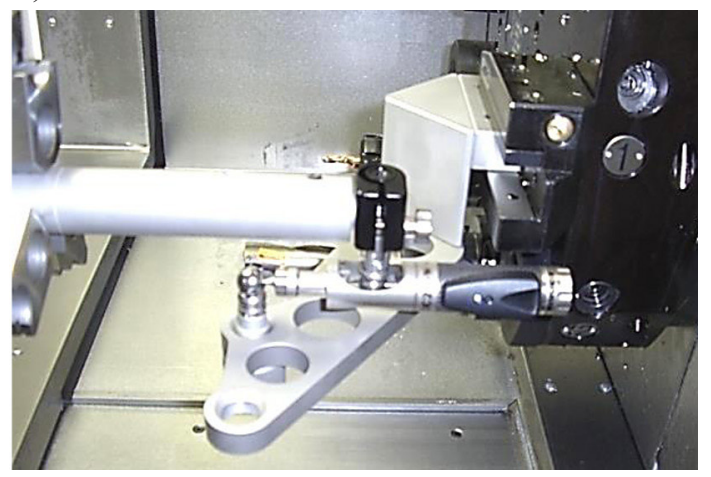

Fig. 5. CNC lathe diagnostics kit: a) tool holder and the holder spindle, b) system mounted on the lathe

ror takes positive values when the angle between two axes in the positive direction is over $90^{\circ}$. The squareness error takes negative values when the angle between two axes in their positive direction is less than $90^{\circ}$. The reason for the squareness error is the deviation of the direction of tested lathe axes (e.g. X and $\mathrm{Y}$ ) from the right angle $90^{\circ}$ in the area of lathe's slideways, where the test is conducted. The deviation of the axis squareness can be of local character or may be the result of the non-misalignment of the lathe's slideways over the whole length of axis. The lathe's axes can also show distortion in the vertical plane (concave, convex or slope), causing local misalignments. The slideways may show excessive wear causing an increase of excessive backlash during motion. The effect of the lathe's squareness error is the lack of mutual squareness of the milled planes. The repair procedure requires the repetition of the test in positions along the slideways of the machine tool in order to determine if the squareness error is local (occurs only in one position) or if it occurs along the whole length of the slideways. If the error is local, it is necessary for machining to be conducted in the area of the slideways, where the influence of the squareness error is the smallest. If the slideways show the squareness er- ror along the whole length, the correction of the slideways' setting should be made, if possible. When the slideways are defective, it is necessary to replace them with new ones.

\section{TEST RESULTS AND ANALYSIS}

Analysis of squareness error measurement results with characteristics

Figure 6 presents the graph of the squareness error of axis. The graph takes the shape of an oval inclined at an angle of $+45^{\circ}$ or $-45^{\circ}$ in relation to $\mathrm{X}$-axis. The inclination is constant and does not change as a result of the change of movement direction [14]. Its variability depends on the feedmotion speed. To determine this error the diagnostic device QC Ballbar with the kinematic bar length $\mathrm{R}=50$ was used.

Figure 7 shows the dependence of changes of the squareness deviation as a function of the feedmotion speed $\mathrm{v}_{\mathrm{f}}$ for the kinematic bar $\mathrm{R}=$ $50 \mathrm{~mm}$. The smallest value was observed for the feedmotion speed $\mathrm{v}_{\mathrm{fl}}=500 \mathrm{~mm} / \mathrm{min}$ and is $-66.2 \mu \mathrm{m} / \mathrm{m}$, then for $\mathrm{v}_{\mathrm{f} 2}=1000 \mathrm{~mm} / \mathrm{min}$ equals $-83.2 \mu \mathrm{m} / \mathrm{m}$, the third measurement for $\mathrm{v}_{\mathrm{f} 3}=1500$ $\mathrm{mm} / \mathrm{min}$ is $-78.4 \mu \mathrm{m} / \mathrm{m}$, and the highest value 


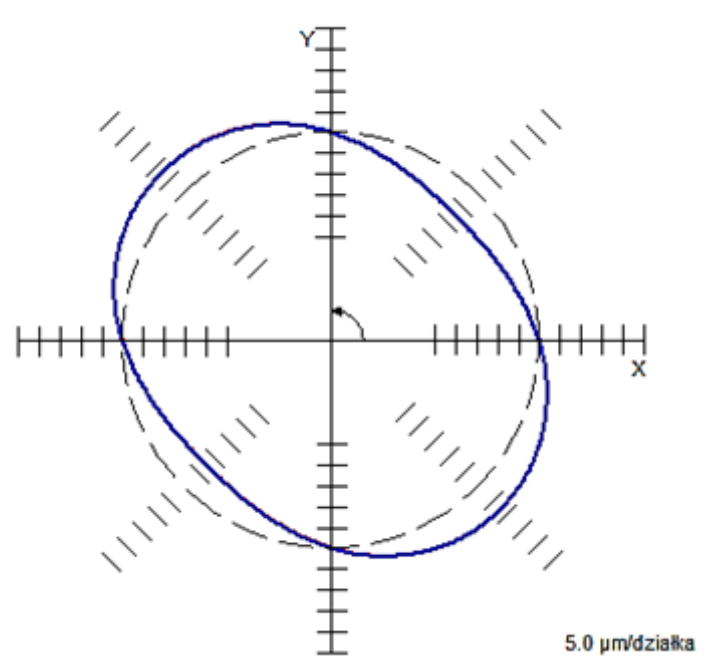

Fig. 6. Example of squareness error diagram [14]

for the feedmotion speed $\mathrm{v}_{\mathrm{f} 4}=2000 \mathrm{~mm} / \mathrm{min}$ and equals $-83.6 \mu \mathrm{m} / \mathrm{m}$. The graphically presented characteristic shows that the squareness error is of non-linear character in relation to the feedmotion speed.

\section{Analysis of reverse spike error measurements}

The reverse spike error occurs when the direction changes. The main reason for the error is too slow a response from the servo drive to the control system signal in the case of the direction change. The pie chart diagram presents it as a temporary leap of deviation, Figure 8 [14].

During the reversal spike error identification the QC Ballbar diagnostics system with the kinematic bar $\mathrm{R}=50 \mathrm{~mm}$ was used.

Figure 9 presents the process of changes of the reversal spike as a function of variable feedmotion speed $\mathrm{v}_{\mathrm{f}^{\prime}}$ The reversal spike in the $\mathrm{Z}$-axis for the requested values of the motion is equal respectively, for $\mathrm{v}_{\mathrm{f} 1}=500 \mathrm{~mm} / \mathrm{min}$ is $-0.2 \mu \mathrm{m}$; for $\mathrm{v}_{\mathrm{f} 2}=1000 \mathrm{~mm} / \mathrm{min}$ is $-0.7 \mu \mathrm{m}$; for $\mathrm{v}_{\mathrm{f} 3}=1500$

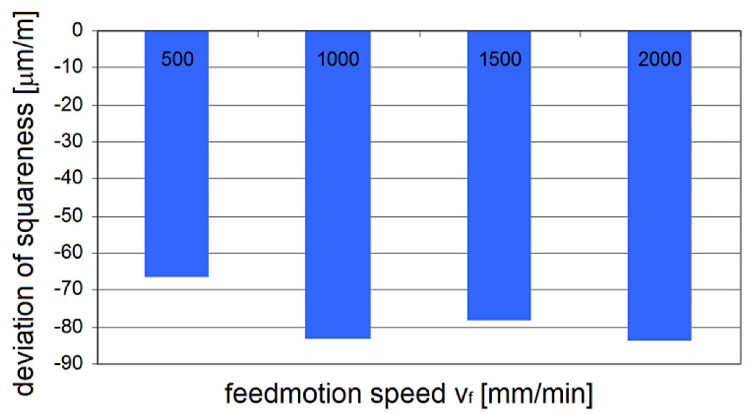

Fig. 7. Changes of squareness error (circle radius $R=50 \mathrm{~mm}$ ) as function of feedmotion speed $v_{f}$

$\mathrm{mm} / \mathrm{min}$ equals $-2.5 \mu \mathrm{m}$; for $\mathrm{v}_{\mathrm{f} 4}=2000 \mathrm{~mm} / \mathrm{min}$ is $-3.7 \mu \mathrm{m}$. It can be stated that the decrease of the value of the reversal spike in Z-axis is almost directly proportional to the increase of the feedmotion speed. In X-axis the values of the reversal spike are of sinusoidal character and are almost equivalent, as they equal respectively: $-1.8 \mu \mathrm{m}$ (for $\mathrm{v}_{\mathrm{fl}}=500 \mathrm{~mm} / \mathrm{min}$ ), $-2.1 \mu \mathrm{m}$ (for $\mathrm{v}_{\mathrm{f} 2}=1000$ $\mathrm{mm} / \mathrm{min}),-1.9 \mu \mathrm{m}$ (for $\left.\mathrm{v}_{\mathrm{f} 3}=1500 \mathrm{~mm} / \mathrm{min}\right),-2.0$ $\mu \mathrm{m}$ (for $\mathrm{v}_{\mathrm{f} 4}=2000 \mathrm{~mm} / \mathrm{min}$ ).

\section{The analysis of the backlash measurement results}

Figure 10 presents the dependence of the backlash on the feedmotion speed. During the circular interpolation, the backlash can be observed in the pie chart as a leap of the motion radius inside out or inside of the curve. This error is caused by the backlash in the drive system of the lathe or in the measuring system, or due to the insufficient inflexibility of both. The most frequent reasons for this error are: the backlash in the screw-cap link, backlash in the gear train of the motor system or the wrong strain of the toothed belt. When the direction of motion changes, one of the axes begins the motion with delay (Fig. 10). This error is ob-

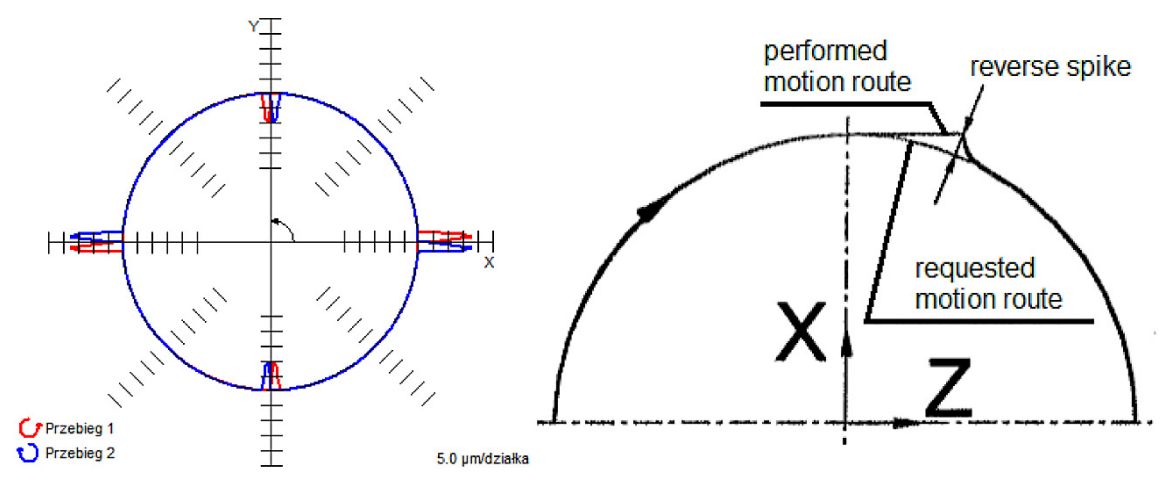

Fig. 8. Reverse spike error diagram: a) process of circle measurement of reverse spike, b) idea of error formation [14] 


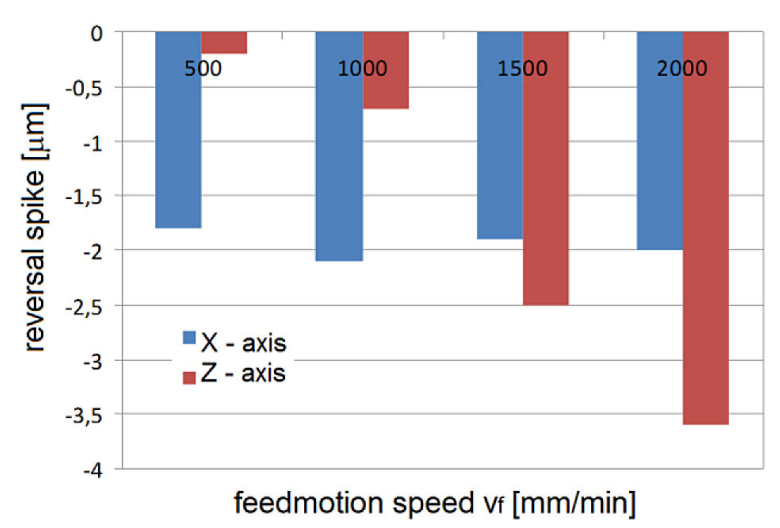

Fig. 9. Dependence of reversal spike as function of feedmotion speed variability in XZ plane of CNC lathe CTX 310 eco by DMG

served specifically in lathes with indirect measuring system. To delete the error it is necessary to remove the cause, that is to delete the backlashes in the measurement or motor system. It is also possible to compensate for the backlash directly in the control system of the lathe but it requires thorough measurement of the positioning accuracy along the entire length of the axis feedmotion [14]. During the reversal spike error identification the QC Ballbar diagnostics system with the kinematic bar length $\mathrm{R}=50 \mathrm{~mm}$ was used.

Figure 11 presents the diagram of changes of the backlash as a function of feedmotion speed variability. The diagram shows that the backlash is of non-linear character. The smallest value for the backlash in X-axis was observed for $\mathrm{v}_{\mathrm{f} 3}=$ $1500 \mathrm{~mm} / \mathrm{min}$ and is $-1 \mu \mathrm{m}$, and for Z-axis for $\mathrm{v}_{\mathrm{f} 2}$ $=1000 \mathrm{~mm} / \mathrm{min}$ and equals $1.9 \mu \mathrm{m}$.

\section{CONCLUSIONS}

The presented test results of the geometric accuracy relate to the numerically controlled CTX 310 eco lathe. QC20-W Ballbar diagnostic kit was the measuring and control device. The tests aimed at defining and characterising main geometric errors of the machine tool, i.e. roundness error, axis squareness error, reverse spike and backlash. Numerous different errors measurements may be carried out using QC20-W Ballbar system. However, the errors analysed here, have the greatest impact on the dimensional and shape accuracy of machining.

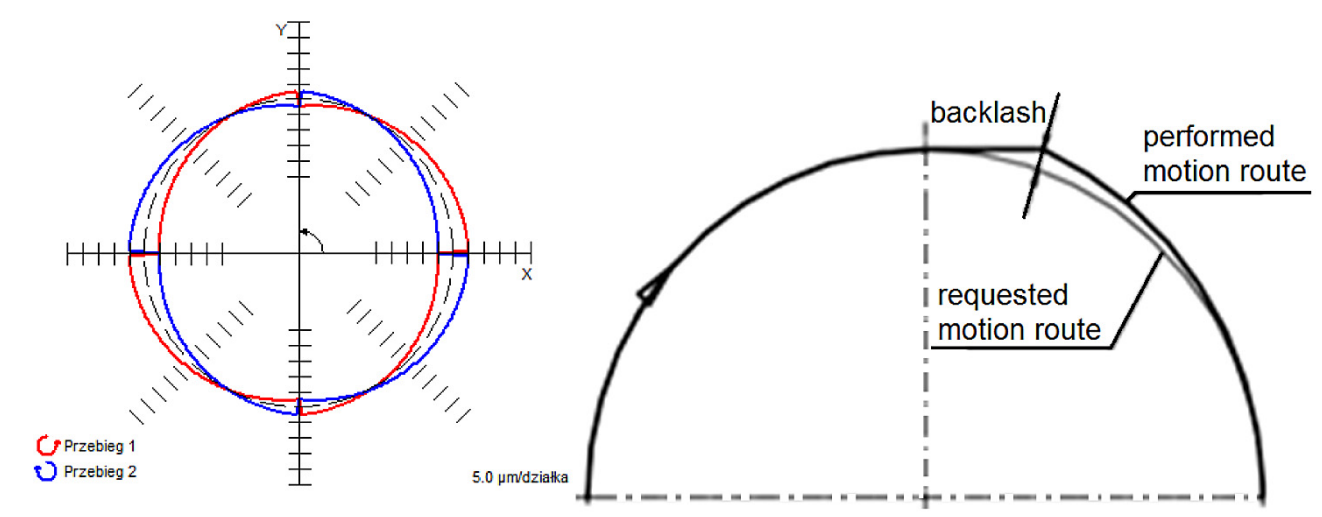

Fig. 10. Schematic example of backlash: a) error diagram, b) reason for error formation [14]

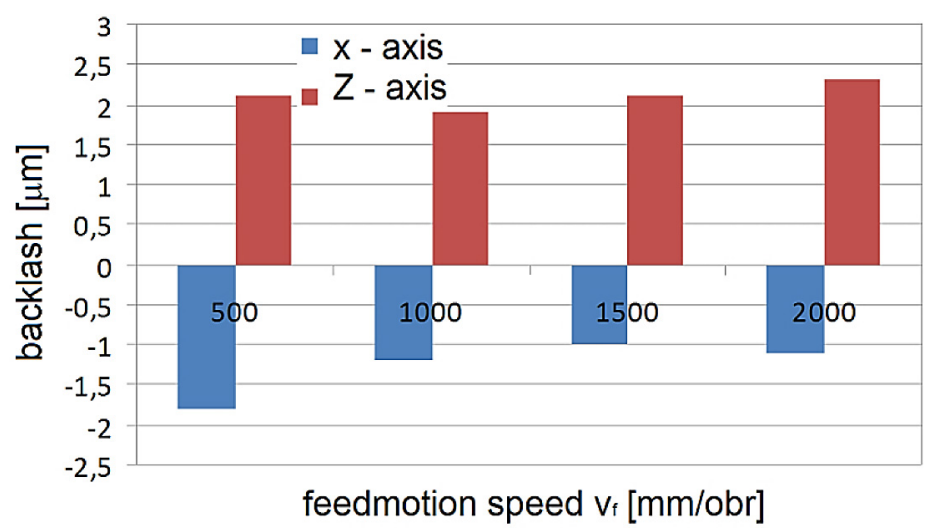

Fig. 11. Backlash as function of feedmotion speed for: measuring radius $R=50 \mathrm{~mm}$, $\mathrm{XZ}$ measurement plane and test angle of $360^{\circ}$ 
The feedmotion speed increase influences the value of the roundness deviation variable, the higher the feedmotion speed, the higher the value of the deviation. In the presented example, for three feedmotion speeds $\mathrm{v}_{\mathrm{f} 1}=500 \mathrm{~mm} / \mathrm{min}, \mathrm{v}_{\mathrm{f} 2}=$ $1000 \mathrm{~mm} / \mathrm{min}, \mathrm{v}_{\mathrm{f} 4}=2000 \mathrm{~mm} / \mathrm{min}$ the value of the roundness error increases slightly and equals: $11.1 \mu \mathrm{m}, 11.3 \mu \mathrm{m}$ and $11.6 \mu \mathrm{m}$ respectively. However, for the adopted feedmotion speed $\mathrm{v}_{\mathrm{f} 3}=$ 1500 the local growth of deviation of up to 13.6 $\mu \mathrm{m}$ takes place, disrupting the linearity of results. This deviation tendency might be caused by local errors of the measuring and control lathe systems.

The squareness error is the second error identified by QC20-W Ballbar system of CTX 310 eco lathe. Figure 7 shows the summary of the results. The presented characteristics show non-linear character of changes of the squareness error value as a function of the feedmotion speed vf.

During the next error identification - the reversal spike - it was noted that the increase of the feedmotion speed is in line with the increasing value of the reversal spike in $\mathrm{Z}$-axis. The value of the reversal spike in $X$-axis remains almost the same. In X-axis the process is of non-linear character and in Z-axis linear (Fig. 9).

The backlash is the next presented error. Figure 11 presents the dependence of the backlash value as a function of the feedmotion speed variability. The given characteristics show non-linear character of the tested function. The diversity of the backlash test results did not show the dependence of the feedmotion speed and the test results.

The errors and the deviations occurring in machine tools constitute a very important issue because they result in the lathe's tooling accuracy and therefore, the quality and precision of machining a particular product.

It can be stated, on the basis of test results, that the roundness deviation depends on the feedmotion speed. To minimise its negative influence on the machine tool performance the reduction of the remaining errors is necessary, as well as making sure if the appropriate motor regulation was set and if the control disruptions do not occur. The reversal spike depends also on the feedmotion speed and, as it results from the Z-axis tests, it changes linearly. It also has a significant influence on the value of the roundness deviation. The reversal spike may be the result of the control system defect and a great delay in the servo drive response. The backlash does not depend on the feedmotion speed. It can result from an incorrect motor regulation, inter alia, wrongly selected backlashes, as well as the backlashes resulting from the lathe's elements wear. The squareness stems from the misalignment of the slideways relative to each other, as well as their wear and deformation. In order to avoid the error increase it is necessary to control the slideways' condition and the correction of their alignment.

CTX 310 eco lathe meets expectations, however, it is hard to state it clearly for the reason that the working area of the machine tool is limited. It prevents more tests using various length of the kinematic bar, and therefore, the measurement had to be made at one measurement position.

\section{REFERENCES}

1. Du Z.C., Hong C.F. Lv M.S.: Research or error moddeling end identification of 3 axis NC machine tools based on cross grind encored measurement. Journal of Physics, Conf. Ser. 48, 2006, 91-100.

2. Florussen G.H.J., Delbressine F.L.M.: Molengraft M.J.G., Schellekens P.H.J. Assessing geometrical errors of multi-axis machines by three-dimensional length measurements. Measurement, 30, 2001, 241-255.

3. Honczarenko J., Kwaśniewicz J.: Nowe systemy pomiarowe do sprawdzania obrabiarek CNC. Mechanik, 12, 2008, 1012-1016.

4. Ibaraki S., Iritani T., Matsushita T.: Error map construction for rotary axes on five-axis machine tools by on-the-machine measurement using a touchtrigger probe. International Journal of Machine Tools and Manufacture, 68, 2013, 21-29.

5. Ibaraki S., Irutani T., Matsushita T.: Calibration of location errors of rotary axes on five-axis machine tools by on-the-machine measurement using a touch-trigger probe. International Journal of Machine Tools and Manufacture, 58, 2012, 44-53.

6. Józwik J.: Ocena odchyłki prostopadłości osi obrabiarki sterowanej numerycznie z wykorzystaniem systemu diagnostycznego QC10 Ballbar. Postępy Nauki i Techniki, 4, 2010, 91-102.

7. Józwik J., Kuric I.: Calibration of 5-axis CNC machine tool by using 3D quickSET measurement system (In print).

8. Józwik J., Pieśko P., Krajewski G. Ocena testu QC10 do kontroli off-line obrabiarek sterowanych numerycznie CNC. Eksploatacja i Niezawodność, 3, 2010, 10-20.

9. Majda P.: Pomiary i kompensacja błędów geometrycznych obrabiarek CNC. Inżynieria Maszyn, 16 (1-2), 2011, 126-134. 
10. Majda P.: The influence of geometric errors compensation of a CNC machine tool on the accuracy of movement with circular interpolation. Adv. in Manufact. Sci. and Technol., 36 (2), 2012, 59-67.

11. Morek R.: Pomiary bezstykowe. Metale \& Nowe Technologie, nr 5, 2012.

12. Spaan1 H.A.M., Florussen G.H.J.: Determining the 5-axes machine tool contouring performance with dynamic R-Test measurements. Proceedings of the $12^{\text {th }}$ Euspen International Conference. IBS Precision Engineering, Stockholm, June 2012.

13. Turek P., Kwaśny W., Jędrzejewski J.: Zaawansowane metody identyfikacji błędów obrabiarek. Inżynieria Maszyn, 5 (1-2), 2010, 8-37.

14. Weikert S.: R-Test, a new device of accuracy measurements on five axis machine tools. CIRP Annales, 53 (1), 2004, 429.

15. http://www.renishaw.com.pl/pl/, access: 15.04.2015 